\title{
Postmortem acinar autolysis in rat sublingual gland: a morphometric study
}

Leticia Rodrigues NERY ${ }^{1}$, Carla Ruffeil MOREIRA ${ }^{2}$, Tania Mary CESTARI ${ }^{3}$, Rumio TAGA ${ }^{4}$, José Humberto DAMANTE ${ }^{5}$

1- DDS, MSc, Graduate Student, Bauru School of Dentistry, University of São Paulo, Bauru, SP, Brazil.

2- DDS, MSc, PhD student, Bauru School of Dentistry, University of São Paulo, Bauru, SP, Brazil.

3- BS, Biologist, Department of Biological Sciences, Bauru School of Dentistry, University of São Paulo, Bauru, SP, Brazil.

4- DDS, PhD, Professor, Department of Biological Sciences, Bauru School of Dentistry, University of São Paulo, Bauru, SP, Brazil.

5- DDS, PhD, Professor, Department of Stomatology, Bauru School of Dentistry, University of São Paulo, Bauru, SP, Brazil.

Corresponding address: Carla Ruffeil Moreira - Departmento de Estomatologia - Faculdade de Odontologia de Bauru, USP - Al. Dr. Octávio Pinheiro Brisolla 9-75 - 17.012-901 - Bauru, SP - Brasil - Phone/fax: +55 (14) 3234-8254 - lerneryl@yahoo.com.br

Received: February 2, 2009 - Accepted: September 5, 2009

\section{ABSTRACT}

bjective: To analyze and to quantify morphological acinar postmortem changes in rat sublingual glands (SLG). Material and Methods: Fifty rats were divided into two groups of 25 animals each. Group I was used for morphological and morphometric evaluations and group II for the determination of gland density and processed gland volume. Acinar autolytic changes were studied at 0 (control group), 3, 6, 12 and $24 \mathrm{~h}$ postmortem periods. The morphometric analysis of the volume density $\left(V_{V}\right)$ and total volume $\left(V_{T}\right)$ of intact (ia) and autolyzed (aa) acini was performed under light microscopy using a Zeiss II integration grid with 100 symmetrically distributed points. Results: Morphologically, temporal progressive nuclear alterations and gradual loss of the structural architecture of acinar cells were found. Regarding quantitative results, both the Vvaa and the Vvia showed statistically significant differences among all postmortem periods $(p<0.05)$. Vvaa increased from $0.42 \%$ at $0 \mathrm{~h}$ to $75.84 \%$ at $24 \mathrm{~h}$ postmortem and Vvia decreased from $71.16 \%$ to $0 \%$ over the same period. For $V$ Taa and $V$ Tia, no statistically significant differences occurred between $12-24 \mathrm{~h}$ and $0-3 \mathrm{~h}(\mathrm{p}>0.05)$, respectively. VTaa increased from $0.18 \mathrm{~mm}^{3}$ at $0 \mathrm{~h}$ to $38.17 \mathrm{~mm}^{3}$ at $12 \mathrm{~h}$, while $V$ tia showed a decrease from 33.47 $\mathrm{mm}^{3}$ to $0 \mathrm{~mm}^{3}$ between 3-24 h postmortem. Data concerning $V$ Tаa were adjusted by twovariable linear regression, obtaining the equation: $y=-3.54+3.38 \times\left(r^{2}=0.90\right)$. The VTaa growth rate calculated by this equation was $3.38 \mathrm{~mm}^{3} / \mathrm{h}$ between $0-12 \mathrm{~h}$. Conclusion: Acinar autolysis on rat SLG demonstrated the most significant signs during the first $6 \mathrm{~h}$ postmortem and was widely spread through the gland at $12 \mathrm{~h}$.

Key words: Rats. Salivary glands. Sublingual gland. Postmortem changes. Autolysis.

\section{INTRODUCTION}

Postmortem autolytic changes have been described in heart ${ }^{1,5,8,12,15}$, temporal bones $^{9}$, pancreas ${ }^{10,14,17}$, kidneys ${ }^{4,17}$, liver ${ }^{17}$, skeletal muscle ${ }^{17}$, blood vessels ${ }^{11}$, blood cells ${ }^{13}$ and sweat glands ${ }^{3}$. Clumping ${ }^{1,3,4,5,11,17}$ and margination of the nuclear chromatin ${ }^{1,3,4,10,12,17}$, pyknotic nuclei ${ }^{1,3,4,10,11}$, breakdown of nuclear membranes ${ }^{4,10}$, swelling or lysis of cells $\mathbf{s}^{1,3,4,9,10,11,12,17}$ and a progressive reduction in cell staining quality ${ }^{6,13,14}$ were some of the events reported in the literature.

In previous investigations on human sublingual glands ${ }^{2,7}$, an eventual phenomenon was identified as autolysis, but the exact meaning of the finding was not elucidated. A lack of information exists concerning postmortem autolytic changes in the mucous and mixed acini of salivary glands, mainly to distinguish these from pathological causes before death or others artifacts. Therefore, the purpose of this study was to analyze and quantify morphological acinar postmortem changes in a rat sublingual gland model (rat SLG) verified at different time intervals after death.

\section{MATERIAL AND METHODS}

This study was approved by the Institutional Committee for Ethics in Animal Experimentation and was performed in accordance with the institutional guidelines for the use of laboratory animals. 


\section{Animals}

Fifty adult male Wistar rats (Rattus norvegicus), weighing approximately $366 \mathrm{~g}$, obtained from the Central Animal House of Bauru School of Dentistry were divided into two groups of 25 animals each. Group I was used for morphological and morphometric evaluations and group II for the determination of the retraction provoked by histological processing and glandular density, both required when calculating processed glandular volume. Groups I and II were divided into subgroups according to the following postmortem periods: 0 (control), 3, 6, 12 and $24 \mathrm{~h}$ (5 rats/period).

\section{General histological procedures}

Prior to anethesia induction, atropine was administered (1.25\% atropine solution, Laboratório Prado AS, Curitiba-PR, Brazil) at a dosage of 4.0 $\mathrm{mg} / \mathrm{kg}$ of body mass. The rats were sacrificed by ketamine hydrochloride (intramuscular injection of $100 \mathrm{mg} / \mathrm{kg}$ of body mass) and xylazine hydrochloride (intramuscular injection of $3 \mathrm{mg} /$ $\mathrm{kg}$ of body mass). The body mass of each rat was determined and the corpses were stored at room temperature $\left(18^{\circ} \mathrm{C}\right)$. At each postmortem time, their sublingual glands were carefully removed and immediately weighed on an analytical scale to obtain the fresh gland mass $(m)$. The glands were fixed in phosphate-buffered $10 \%$ formalin solution for 1 week at room temperature. Subsequently, the specimens were dehydrated in ethanol, cleared in xylol and embedded in Histosec-Merck (Merck KGaA, Darmstadt, Germany). Alternate 5- $\mu$ m-thick sections at $100-\mu \mathrm{m}$ intervals were obtained and stained with hematoxylin-eosin.

\section{Calculation of processed gland volume}

The processed gland volume $(V P)$ was calculated for each gland using the following equation: $V p=m / d \times r f$, where $m$ is the fresh gland mass, $d$ is the glandular density and $r f$ is the shrinkage caused by histological processing.

Glandular density (d) was evaluated in the group II glands at the established postmortem periods using a Mettler Toledo AT261 Delta Rang (Mettler Toledo, Barcelona, Spain) precision scale fitted with the appropriate accessories for density determinations. The average density obtained for the periods was $1.046 \mathrm{mg} / \mathrm{cm}^{3}$. The retraction caused by the histological procedures was evaluated using the method described by Taga and Sesso ${ }^{16}$ (1978). In this method, linear measurements are obtained from the square trimmed fresh organ (Sf) and after histological processing (Sp). The averages of the Sf and Sp linear values are raised to the third power. The retraction factor ( $r$ ) was estimated using the relationship: $r f=\mathrm{Sp}^{3} / \mathrm{Sf}^{3}$. The mean $r f$ was 0.625 .
Morphometric evaluation of the acinar volume density $(V v)$ and total volume $(V T)$

The $V v$ of the acini of each sublingual gland was determined using an Olympus light microscope (Olympus America Inc., New York, NY, USA) with a 100x objective and $8 x$ Zeiss $\mathrm{Kpl}$ eyepiece containing a Zeiss II integration grid (Carl Zeiss Jena $\mathrm{GmbH}$, Jena, Germany) with 10 parallel lines and 100 points symmetrically distributed over a quadrangular area. In fifty histological fields per rat, selected by systematic randomization proceedings ${ }^{18}$, the number of points $(P)$ coinciding with the images of intact (ia) and autolyzed (aa) acini were counted. The total number of points $\left(P_{T}\right)$ over total gland area was also obtained. $V_{V}$ was calculated by the equation: $V V=P / P_{T}$. Once the $V_{V}$ and processed gland volume $(V P)$ values were determined, $V_{T}$ was calculated $\left(\mathrm{mm}^{3}\right)$ by the equation: $V_{T}=V V \times V_{P}$.

\section{Adopted criteria of intact and autolyzed acini}

An acinus was counted as autolyzed when it presented the minimum sign of loss of cell limit, independent of the degree. For morphometric analysis, the following criteria were adopted: a) intact acini: included mixed or mucous intact acini. They were quantified as only one variable; b) autolyzed acini: included mixed or mucous autolyzed acini; c) other: these included ducts, blood vessels, nerves, inflammatory infiltrated and stroma, which were represented by the connective tissue. Eventual artifacts were also computed here.

\section{Statistical analysis}

The results obtained for postmortem periods were compared by one-way ANOVA or KruskalWallis followed by Student-Newman-Keuls using the Sigma Stat Jadel ${ }^{\mathrm{TM}}$ Scientific software for Windows (Jadel Corporation, Chicago, IL, USA). The level of significance was set at 0.05. The data for total volume of autolyzed acini were submitted to fitting by two-variable linear regression $\left(y=a_{0}+a_{1} x\right)$ using Sigma-Stat software. The quality of the fit was assessed by the determination coefficient $\left(r^{2}\right)$.

\section{RESULTS}

No statistically significant differences were observed for body mass $(p=0.145)$ and glandular density $(p=0.161)$ between all the postmortem periods. Results for glandular mass are shown in Table 1. Glandular mass increased by $26.2 \%$ $(p<0.01)$ between 0 and $6 \mathrm{~h}$, stabilizing thereafter $(p>0.05)$. The processed gland volume increased by $17.1 \%(p<0.01)$ between 0 and $12 \mathrm{~h}$, remaining constant between 12 and $24 \mathrm{~h}(\mathrm{p}>0.05)$. 


\section{Qualitative findings}

The SLG collected immediately after sacrificing the rats (Figure $1 \mathrm{~A}$ ) were intact and presented mixed acini, mucous acini, ducts and small quantities of conjunctive material between these. The mixed acini presented larger mucosa cells than the serous cells, which were well-defined, presenting abundant cytoplasm and eliptical nuclei, while the serous cells grouped in half-moon form were located in the peripheral portion of the acini, presenting small eosinophilic cytoplasm and central spherical nuclei. Rat glands at $3 \mathrm{~h}$ postmortem presented initial signs of acini destruction. Some mucous cells presented granulations, irregular spaces in the cytoplasm and loss of cell limit integrity (Figure 1B). The serous cells presented aspects similar to $0 \mathrm{~h}$ and the ducts exhibited an advanced stage of autolysis, including granular cytoplasm cells, loss of cell limits and nuclei alterations. In the $6 \mathrm{~h}$ postmortem group (Figure 1B), the glands presented morphological characteristics similar to the $3 \mathrm{~h}$ postmortem period. The nuclei presented karyorrhexis, irregular distribution of chromatin, which formed clumping along the nuclei periphery, and loss of limits.

After $12 \mathrm{~h}$ (Figures 1C and 1D), almost all the acini presented intermediary stage autolysis, despite the external limits remaining well-defined. Within the acini, the mucous cells showed partial or complete loss of limits and disorganized cytoplasm. Some nuclei presented karyorrhexis and others were pyknotic and hyperchromatic due to high chromatin condensation. In the $24 \mathrm{~h}$ postmortem group (Figures $1 \mathrm{E}$ and $1 \mathrm{~F}$ ), the acini presented an advanced stage of autolysis. Areas presenting the complete disappearance of acinus external limits were observed. The cytoplasmatic contents had overflowed and contained dispersed pyknotic nuclei. However, in other areas, acinus limits were maintained. In this phase it was difficult to

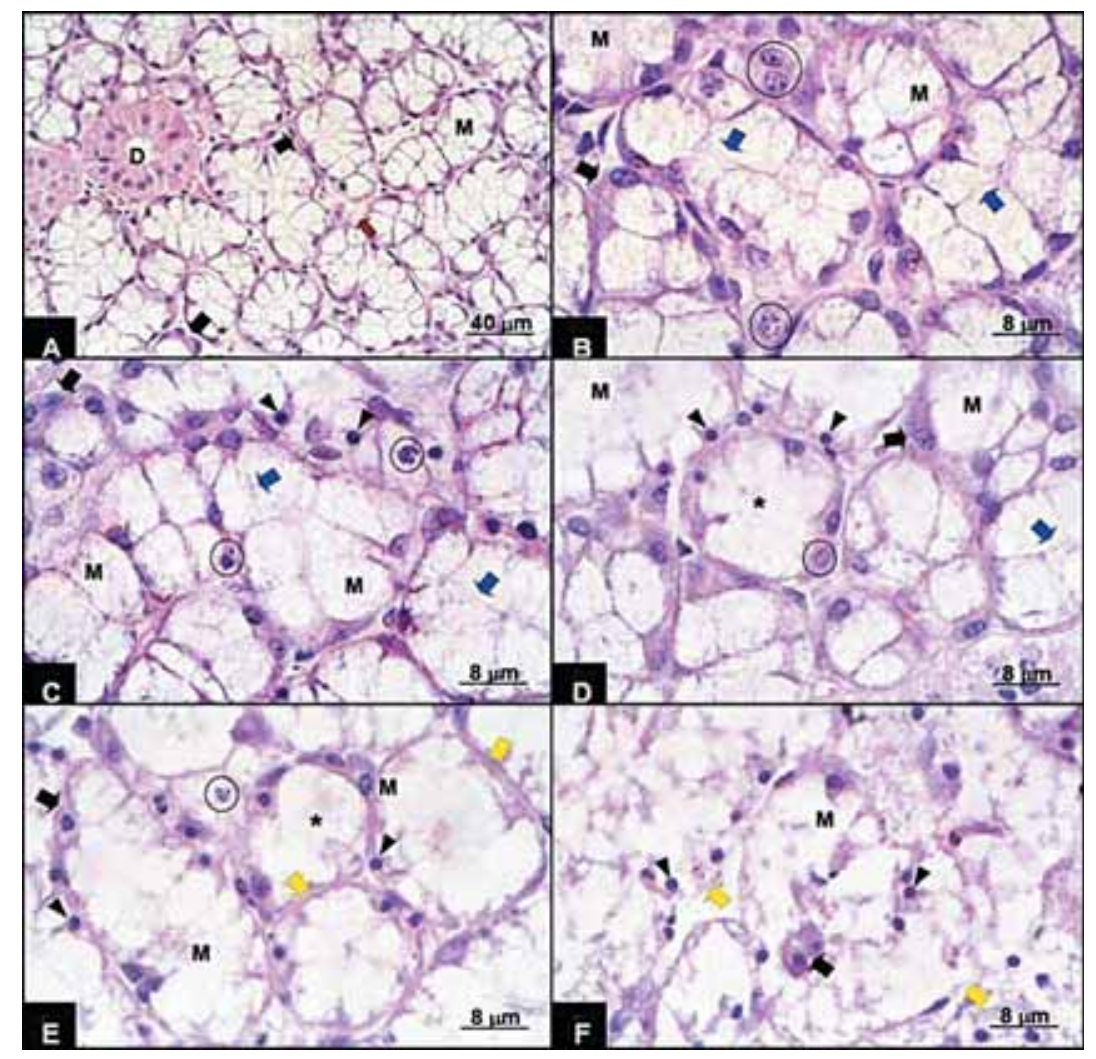

FIGURE 1-Sublingual gland A - 0 h: the glandular structure presents integrity, exhibiting mixed acini with large mucous cells (M) and small half-moon serous cells (full arrow) and intralobular ducts (D) interlaced by stroma (reed arrow). HE; B - 3 and $6 \mathrm{~h}$ : mixed acini exhibiting some mucous cells (M) presenting loss of integrity of their external limit (blue arrow) and integral serous cells (full arrow); C - $12 \mathrm{~h}$ : mixed acini exhibiting mucous cells (M) presenting loss of integrity of their external limit (blue arrow), karyorrhexis (circle) and pyknosis (arrowhead) and serous cells presenting karyorrhexis (full arrow). HE; D - 12 h: mixed acini exhibiting mucous cells (M) presenting loss of integrity of their external limit (blue arrow) and others showing total disintegration of the external limit (asterisk), karyorrhexis (circle) and pyknosis (arrowhead) and serous cells presenting pyknotic nuclei (full arrow). HE; E - 24 h: Disorganization of glandular in relation to the previous figure, exhibiting mixed acini retaining their limits (yellow arrow), exhibiting mucous cells (M) presenting total and disintegration of the external limit (asterisk), karyorrhexis (circle) and pyknosis (arrowhead) and serous cells presenting pyknotic nuclei (full arrow). An acinus showing a single remaining nucleus was noted. HE; F - 24 h: Complete disorganization of the glandular structure, exhibiting acini presenting external limit rupture (yellow arrow) complete disorganization of the cellular content and integral serous cells dispersed in the amorphous resulting from mucous cell destruction. Hematoxylin-eosin 


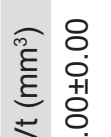

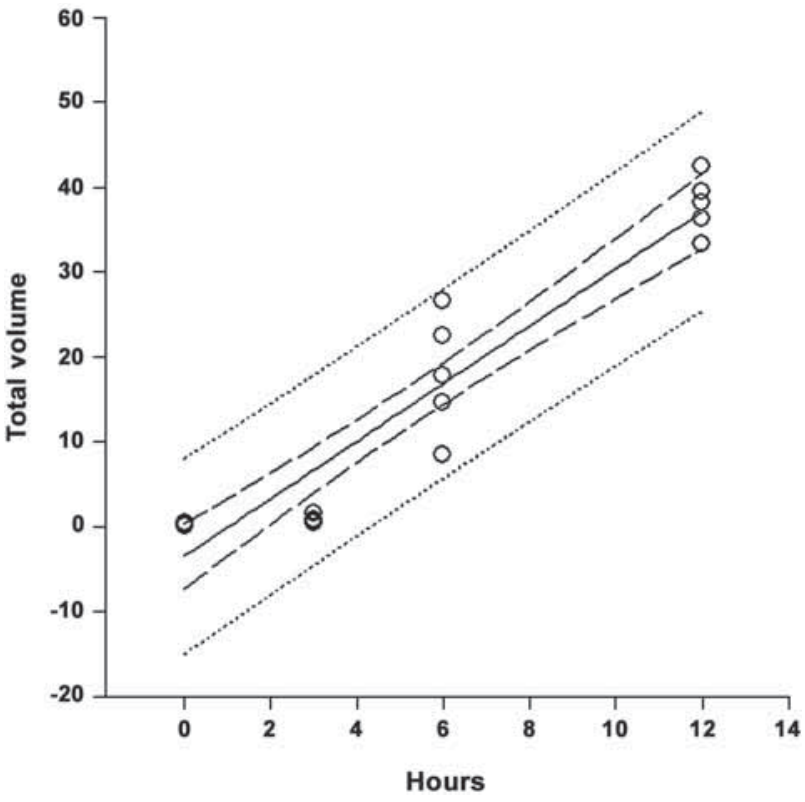

FIGURE 2- Linear regression analysis of the total volume of autolyzed acini from 0 to $12 \mathrm{~h}$ postmortem

distinguish the stromal parenchyma.

\section{Quantitative results}

The results of the morphometric analysis are shown in Table 1. Both the Vvaa and the Vvia showed statistically significant differences among all postmortem periods $(p<0.05)$. Only the Vvia between 0 and $3 \mathrm{~h}$ were not statistically significant. The Vvaa increased from $0.42 \%$ at $0 \mathrm{~h}$ and to $1.48,38.72,67.50$ and $75.84 \%$ at $3,6,12$ and $24 \mathrm{~h}$ postmortem, respectively. The $V$ via showed the opposite trend, presenting $71.16 \%$ at $0 \mathrm{~h}$ and decreasing to $70.40,35.12,4.70$ and $0.00 \%$ at 3 , 6,12 and $24 \mathrm{~h}$ postmortem, respectively.

For the Vтаa and the Vтia, no statistically significant differences occurred between 12-24 h and $0-3 h(p>0.05)$, respectively. The $V$ Taa increased from $0.18 \mathrm{~mm}^{3}$ at $0 \mathrm{~h}$ to $0.73,17.77$ and 38.17 $\mathrm{mm}^{3}$ at 3, 6 and $12 \mathrm{~h}$ postmortem, respectively. The Vtia showed stable values between 0 (31.52 $\mathrm{mm}^{3}$ ) and $3 \mathrm{~h}\left(33.47 \mathrm{~mm}^{3}\right)$ decreasing to 17.97, 2.61 and $0.00 \mathrm{~mm}^{3}$ at 6,12 and $24 \mathrm{~h}$ postmortem, respectively.

The equation obtained through linear regression analysis for the VTaa was: $y=-3.54+3.38 x$ (Figure $2)$. The $V$ taa in the period from $0-12 \mathrm{~h}$ postmortem increased at a rate of $3.38 \mathrm{~mm}^{3} / \mathrm{h}$.

\section{DISCUSSION}

Autolysis is normally associated with autopsies and recognition of the phenomenon is very important $\mathrm{t}^{12,15}$ to elucidate forensic cases ${ }^{19}$. Thus, autolytic changes have been investigated by forensic pathologists, because they may assist in determining the time of death, especially in the first few $\mathrm{h}$ postmortem ${ }^{3,17}$. 
Although postmortem autolysis depends on various factors ${ }^{9,17}$, the most important factor is the postmortem period $8,9,14$. The literature reporting on the severity of autolysis during postmortem time has been investigated in functional ${ }^{1,10,12}$, light microscopic ${ }^{3,4,11-14}$ and electron microscopic studies $^{1,3-5,8-10,12,13,15,17}$ in both humans h $^{3,9,14}$ and animals $s^{1,4,5,8,10-12,15,17}$. Despite some quantitative studies in various organs or tissues ${ }^{8,11,13,15}$, a morphometric study more specifically related to mucous salivary glands that describes the sequence of postmortem autolytic events is lacking. Thus, in the present study, the increase in the postmortem time was correlated with morphometric evaluation of autolytic changes in the mucous and mixed acini of the rat sublingual gland. Intact and autolyzed acini were counted to measure the phenomenon.

Rat body mass presented no statistically significant differences between the groups studied $(p=0.145)$, thus showing sample homogeneity regarding the size and age of the rats. Glandular mass showed a mean increase of $34.3 \%$ from 0 to $24 \mathrm{~h}$ postmortem, suggesting the incorporation of liquids originating from the interstices or surrounding tissues. Autolysis promotes increased concentration within the organ, attracting liquids, leading to the increase in mass.

The present qualitative results followed the general line of descriptions of other works regarding different cells and organs ${ }^{1,3-5,9-12,17}$. At $0 \mathrm{~h}$ postmortem, the glandular structure was practically intact. An increase in the postmortem period presented loss of cell limit integrity, eventually followed by its disappearance. In parallel, the presence of granulations in the cytoplasm and nuclei alterations increased, culminating in total disorganization of the glandular structure at $24 \mathrm{~h}$ postmortem (Figure 1). Some of these postmortem autolytic changes were similar to alterations also described as apoptosis ${ }^{4,17}$ and inadequate/delayed fixation ${ }^{6,9,11}$. As stated by Margarone, et al. ${ }^{6}$ (1985), acini of minor salivary glands are specially susceptible to delay in fixation, therefore presenting artifacts similar to postmortem autolytic changes.

Nuclear alterations similar to apoptosis, ${ }^{4,17}$ or fixation artifacts $^{1}$, such as peripheral chromatin condensation, have been described for different organs of the body, including the pancreas, kidneys and heart. Early nuclear autolytic changes in postmortem are margination and condensation of chromatin against the nuclear membrane and later changes include rupture of nuclear membrane and chromatolysis. Nevalainen and Anttinen ${ }^{10}$ (1977) suggested that perichromatin filaments and granules are the nuclear structures most susceptible to autolytic degradation. It should be pointed out that nuclear changes were observed here in SLG acinar cells (Figure 1) and previously in pancreatic acinar cells ${ }^{10,17}$.

The present results showed more severe autolytic changes in the striated and excretory ducts than in the acini. This suggests a different rate of autolysis in rat SLG structures, similar to previously reported situations involving different animal and human organs $s^{4,9,11,17}$. According to Sukura, et al. ${ }^{4}$ (1990), these temporal differences can be partially explained by oxygen deletion modifying cell metabolism in a specific way within tissues. Cells rich in digestive enzymes are most readily subject to autolytic changes after death. Lysosomes might burst within injured, still living, cells. In spite of this, Tomita, et al. ${ }^{17}$ (2004) found that pancreas cells, which present a high content of hydrolytic enzymes, were relatively resistant to postmortem change up to $24 \mathrm{~h}$ after death. They also demonstrated that changes observed under a light microscope occurring during the early postmortem period are organ-specific for up to 24 h after death.

In contrast to the present results regarding SLG ducts, previous observations in human salivary glands suggested that autolytic changes in duct cells seams to be less accelerated when compared to acini cells ${ }^{2,3,7}$. Ultrastructurally, even the same cellular organelle demonstrated varying resistance to autolysis depending on the cell type ${ }^{9}$. Regarding acinus cells, greater resistance to autolysis occurred in serous cells compared to mucous cells, both in humans ${ }^{2,7}$ and rats (Figure 1 ). In blood figure elements, clear differences were found among platelets and red and white cells. Lymphocytes seemed to present the highest resistance in comparison with the other white cells ${ }^{13}$.

Various types of blood and other human cells retain their morphological structure and viability for long periods after death ${ }^{13}$. Minimal or no morphological changes were observed for at least three $\mathrm{h}$ after death in different cells $\mathbf{s}^{1,3,4,11}$. In the present study, isolated autolytic changes were found even in the $0 \mathrm{~h}$ group. Pallot, et al. ${ }^{11}$ (1992) also found isolated alterations in the cells of rat carotid body. These authors stated that some cells showed autolytic changes within the few minutes required to complete organ dissection. Armiger, et al. ${ }^{1}$ (1976) reported mild nuclear changes in some control specimens and attributed them to fixation artifacts. We agree with these authors and speculate that SLG manipulation during dissection could promote the occurrence of these phenomena.

In this study, numerical analysis of the evolution of the $V_{\text {Taa }}$ and the $V$ tia showed that at $3 \mathrm{~h}$, only $2.0 \%$ of the $V_{T}$ of the total acini were autolyzed, increasing to $53.8 \%, 93.0 \%$ and $100 \%$ at 6,12 and $24 \mathrm{~h}$ postmortem, respectively. Thus, half the acini of rat sublingual glands already presented autolysis at $6 \mathrm{~h}$ postmortem, with the greatest rate occurring between 3 and $6 \mathrm{~h}$, and almost total autolysis at $12 \mathrm{~h}$ postmortem. This demonstrates the fragility of SLG in relation to postmortem modifications. The increase in acini autolysis rate calculated using the adjusted linear equation: $y=-$ $3.54+3.38 x$ was $3.38 \mathrm{~mm}^{3} / \mathrm{h}$. Thus, VTaa increased 
significantly in the 0 to $12 \mathrm{~h}$ postmortem period at a mean velocity of $3.38 \mathrm{~mm}^{3}$ per $\mathrm{h}$.

The morphological alterations caused by autolysis demonstrated here (Figure 1) could help researchers and pathologists recognizing the phenomena and discard pathological areas and other artifacts. Further ultrastructural studies would be helpful to characterize the sequence of microstructural postmortem changes in sublingual glands, possibly including smaller postmortem periods. From the above comments it is evident that many changes in autolytic rat SLG acinar cells are very similar to those observed during the autolysis of many other cell types.

\section{ACKNOWLEDGEMENTS}

The authors would like to thank FAPESP (Nery LR, 05/53340-7) and CAPES (Moreira CR) for providing scholarships. They would also like to thank the professors and employees of the Department of Biological Sciences of Bauru School of Dentistry for their assistance.

\section{REFERENCES}

1- Armiger LC, Seelye RN, Carnell VM, Smith CU, Gavin JB, Herdson PB. Morphologic and biochemical changes in autolysing dog heart muscle. Lab Invest. 1976;34(4):357-62.

2- Azevedo LR, Damante JH, Lara VS, Lauris JR. Age-related changes in human sublingual glands: a post mortem study. Arch Oral Biol. 2005;50(6):565-74.

3- Cingolani M, Osculati A, Tombolini A, Tagliabracci A, Ghimenton $C$, Ferrara SD. Morphology of sweat glands in determining time of death. Int J Legal Med. 1994;107(3):132-40.
4- el-Shennawy IE, Gee DJ, Aparicio SR. Renal tubular epithelia ultrastructure in autolysis. J Pathol. 1985;147(1):13-21.

5- Hibbs RG, Black WC. Electron microscopy of post-mortem changes in the rat myocardium. Anat Rec. 1963;147:261-72.

6- Margarone JE, Natiella JR, Vaughan CD. Artifacts in oral biopsy specimens. J Oral Maxillofac Surg. 1985;43(3):163-72.

7- Moreira CR, Azevedo LR, Lauris JR, Taga R, Damante JH. Quantitative age-related differences in human sublingual gland. Arch Oral Biol. 2006;51(11):960-6.

8- Muñoz DR, Almeida M, Lopes EA, Iwamura ES. Potential definition of the time of death from autolytic myocardial cells: a morphometric study. Forensic Sci Int. 1999;104(2-3):81-9.

9- Nadol JB Jr, Burgess B. A study of postmortem autolysis in the human organ of Corti. J Comp Neurol. 1985;237(3):333-42.

10- Nevalainen TJ, Anttinen J. Ultrastructural and functional changes in pancreatic acinar cells during autolysis. Virchows Arch B Cell Pathol. 1977;24(3):197-207.

11- Pallot DJ, Seker M, Abramovici A. Post-mortem changes in the normal rat carotid body: possible implications for human histopathology. Virchows Arch A Pathol Anat Histopathol. 1992;420(1):31-5.

12- Penttilà A, Ahonen A. Electron microscopical and enzyme histochemical changes in the rat myocardium during prolonged autolysis. Beitr Pathol. 1976;157(2):126-41.

13- Penttilå A, Laiho K. Autolytic changes in blood cells of human cadavers. II. Morphological studies. Forensic Sci Int. $1981 ; 17(2): 121-32$

14- Shimizu M, Hayashi T, Saitoh Y, Ohta K, Itoh H. Postmortem autolysis in the pancreas: multivariate statistical study. The influence of clinicopathological conditions. Pancreas. $1990 ; 5(1): 91-4$

15- Sukura A, Soveri T, Lindberg LA. Morphometric quantitation of early autolytic changes in rat myocardial cells. Res Vet Sci. $1990 ; 48(3): 276-9$

16- Taga R, Sesso A. Cell population growth in the rat parotid gland during postnatal development. Arch Oral Biol. 2001;46(10):90918.

17- Tomita Y, Nihira M, Ohno Y, Sato S. Ultrastructural changes during in situ early postmortem autolysis in kidney, pancreas, liver, heart and skeletal muscle of rats. Leg Med (Tokyo). 2004;6(1):25-31.

18- Weibel ER. Stereological principles for morphometry in electron microscopic cytology. Int Rev Cytol. 1969;26:235-302.

19- Yamamoto $K$, Yamamoto $Y$, Matsumoto $H$, Hayase $T$, Ojima $\mathrm{K}$, Matsubayashi $\mathrm{K}$, et al. Unusual post-mortem autolytic change in the liver: wavy transformation of hepatocytes. Med Sci Law. $1997 ; 37(3): 256-9$. 